\title{
Anaemia in pregnancy and associated factors: a cross sectional study of antenatal attendants at the Sunyani Municipal Hospital, Ghana
}

Peter Anlaakuu ${ }^{1,2}$ and Francis Anto ${ }^{1 *}$ (i)

\begin{abstract}
Background: Anaemia in pregnancy is an important health issue resulting in high maternal morbidity and mortality. The purpose of the current study was to identify factors associated with anaemia among pregnant women receiving antenatal care at the Sunyani Municipal Hospital in Ghana.

Methods: A cross-sectional study involving pregnant women seeking antenatal care at the Sunyani Municipal Hospital was conducted between May and June, 2015. It involved the collection of data on socio demographic and obstetric variables, medical interventions and malaria infection, consumption of iron containing foods and supplements using a case record form and a structured questionnaire. Also, data on haemoglobin concentrations at first and current antenatal visit were collected. Bivariate and multivariate statistical analysis were done to determine factors associated with anaemia.

Results: Out of the 316 participants, 129 (40.8\%) were found to be anaemic ( $\mathrm{Hb}<11.0 \mathrm{~g} / \mathrm{dl}$ ) at the time of their first ANC visit (mean Hb: $11.21 \mathrm{~g} / \mathrm{dl}$, range 6.8-15.1 g/dl). Seventy-nine (61.2\%) of them had mild anemia (Hb 9.0-10.9 g/ dl), 48 (37.2\%) had moderate anemia ( $\mathrm{Hb} 7.0-8.9 \mathrm{~g} / \mathrm{dl}$ ) whilst $2(1.6 \%)$ had severe anemia $(\mathrm{Hb}<7.0 \mathrm{~g} / \mathrm{dl})$. During their most recent ANC visit, the prevalence of anaemia was found to be similar to that of the first visit with 131 (41.5\%) of them being anaemic [mean Hb: $11.24 \mathrm{~g} / \mathrm{dl}$, range 8.10-14.5 g/dl]. The haemoglobin levels however improved significantly during the most recent visit compared to the first with none of the women being severely anaemic ( $\mathrm{Hb}<7.0 \mathrm{~g} /$ dl). The prevalence of moderate anaemia reduced from $37.2 \%$ (Cl 28.9-46.2) during the first visit to 19.1\% (12.7-26.9) during the most recent visit, a reduction of $48.7 \%$. Malaria infection, frequency at which one consumed fish/snails and gestational age at first ANC visit were the main factors found to be associated with anaemia among the pregnant women.
\end{abstract}

Conclusions: Malaria infection, fish/snails intake and gestational age at first ANC visit were significantly associated with anaemia. Addressing these factors can reduce the incidence of anaemia in pregnancy.

Keywords: Anaemia in pregnancy, Malaria infection, Intake of fish and snail, Antenatal visits

\section{Background}

Anaemia is a major public health problem with about two billion people being anaemia worldwide [1]. The global prevalence of anaemia in pregnancy is estimated

*Correspondence: fanto@ug.edu.gh
1 School of Public Health, University of Ghana, Legon, Ghana
Full list of author information is available at the end of the article to be approximately $41.8 \%$ varying from a low of $5.7 \%$ in the United State of America to a high of $75 \%$ in Gambia [2]. Some women are anaemic even before they become pregnant and others become progressively anaemic during pregnancy [3]. Infectious diseases such as malaria, helminths infestations, and HIV have been implicated in the high prevalence of anemia in sub-Saharan Africa [4]. 
Anaemia is an important risk factor in pregnancy and it is associated with an increased incidence of both maternal and foetal morbidity and mortality. More than three percent of maternal mortality in Africa are directly attributable to anaemia [5]. Maternal anaemia also contributes to an increase in perinatal mortality, low birth weight, still birth and foetal wastage. Anaemia in pregnancy reduces tolerance to blood loss and leads to impaired function and cardiac failure [6].

Anemia prevalence data remains an important indicator in public health since anemia is related to morbidity and mortality in the population groups usually considered to be the most vulnerable; pregnant women and children under five. Anemia prevalence study is also useful to monitor the progress of reproductive health. Despite efforts being made to reduce the burden of anemia, its prevalence is still high in developing countries. Thus, the objective of this study was to determine factors associated with anemia among pregnant women who sought antenatal care (ANC) in the Sunyani Municipal Hospital, a facility that serves both rural and urban populations in the Brong Ahafo region of Ghana.

\section{Methods}

\section{Study area}

The study was conducted in the Sunyani Municipal Hospital in the Brong Ahafo region of Ghana. The hospital's bed capacity is 63 , with an average outpatient attendance of 1300 per day. There are 265 professional nurses, five doctors, six physician assistants, twenty-two midwives and eight community health nurses. Routine antenatal services provided include Intermittent Preventive Treatment for malaria in Pregnancy (IPTp), health education, immunization, and monitoring of haemoglobin levels of the women.

\section{Study design}

A hospital based cross sectional study was conducted at the Sunyani Municipal Hospital from May to June 2015. All pregnant women aged 15 years and above who visited the antenatal clinic of the hospital during the period were eligible to participate in the study. Primary data were collected from the women as well as a review of their antenatal records.

\section{Sample size estimation and sampling}

The sample size was estimated using the prevalence of anaemia in pregnancy reported for the region (29.0\%) [7]. Using the Cochran formula, $n=\left(Z^{2} p q\right) / d^{2}$ [8], where: $\mathrm{n}=$ sample size, $\mathrm{Z}=$ the $\mathrm{z}$-score that corresponds with 95\% confidence interval (1.96), $\mathrm{P}=$ proportion of anaemia in pregnancy $(29.0 \%,=0.29), \mathrm{q}=$ proportion of antenatal attendants who are not anaemic $(1-0.29 \%,=0.71)$, $\mathrm{d}=$ margin of error set at 5\% (0.05), a sample size of $\mathrm{n}=316$ was estimated.

Thirteen participants were randomly selected on each day of data collection from an average of 60 antenatal attendants using a sampling interval of five. The first participant was randomly selected among the first five who reported for antenatal care on each day. The subsequent fifth was selected until 13 participants were enrolled for the day. Participants who did not consent to participate in the study were replaced with the next person following her. This was repeated until the required sample was obtained.

\section{Data collection methods and tools}

Data on socio-demographic characteristics such as age, educational level, number of children, occupation, marital status, frequency of taking iron containing foods and bed net usage were collected directly from the mothers onto a questionnaire designed specifically for this study.

The questionnaire was developed based on the key indicators of the study and reviewed by colleagues with expertise in epidemiology, nutrition and malarialogy. Some variables that have been identified in earlier studies in Ghana and elsewhere in Africa to influence anaemia in pregnancy were included $[3,4]$. The questionnaire consisted of partially categorised questions divided into three sections, namely: socio-demographic; nutritional and malaria prevention practices and previous and current obstetric history. The data were collected after the women had received ANC services for the day. The data collection was carried out by trained research assistants with university degrees, who are fluent in the local language Akan and English. For the purpose of accuracy, some relevant data were extracted from the ANC booklets. These included, number of ANC visits, gravidity, parity, haemoglobin concentration at first and current visits, gestational age at first and current $\mathrm{ANC}$ visit and administration of anti-helminths during current pregnancy. Additional data included malaria infection during current pregnancy, administration of iron supplementation and gestational age at which first (Intermittent Preventive Treatment in pregnancy (IPTp) was administered.

\section{Quality control}

Quality control was conducted by pre-testing the questionnaire to determine its appropriateness and suitability for the study. This resulted in corrections, rephrasing of questions and rearrangement of sections in the questionnaire. Pre-testing was done using 20 ANC attendants over a period of 2 days (10/day) at the SDA hospital, a health facility also located in the Sunyani Municipality and providing similar health services. To ensure uniformity of the process, the two data collectors involved in the 
study were trained for 5 days on how to explain the study objectives, conduct the interviews and obtain informed consent. Data extracted from the ANC books were verified by a supervisor at the facility.

\section{Data processing and analysis}

Data were entered into Epi Data version 3.1 and exported to Stata version 12 for analysis. Categorical variables were summarized into frequencies and proportions. Continuous variables were summarized into means and ranges. Continuous variables such as age were categorized into age groups, $\mathrm{Hb}$ values were categorized into anaemia $(\mathrm{Hb}$ $<11.0 \mathrm{~g} / \mathrm{dl}$ ), mild anaemia ( $\mathrm{Hb} 10-10.9 \mathrm{~g} / \mathrm{dl}$ ), moderate anaemia $(7-9.9 \mathrm{~g} / \mathrm{dl})$ and severe anaemia $(\mathrm{Hb}<7 \mathrm{~g} / \mathrm{dl})$ [1]. Bivariate analysis was done using Pearson Chi square tests to assess significant differences between anaemia and categorical variables. Binary logistic regression was used to assess for factors associated with anaemia. Factors with $\mathrm{p}<0.05$ at $95 \% \mathrm{CI}$ were considered statistically significant and therefore included in the multiple logistic regression model.

\section{Inclusion/exclusion criteria}

All pregnant women aged 15 years and above with at least two antenatal visits and record of $\mathrm{Hb}$ concentration at first and current visit were eligible to participate in the study. Pregnant women who had history of blood transfusion (within the previous 2 weeks) and those who declined consent were excluded.

\section{Results}

\section{Socio-demographic and obstetric characteristics of study participants}

A total of 316 pregnant women aged $15-45$ years (mean 28.42 years and $\mathrm{SD} \pm 5.6$ years) accessing antenatal care (ANC) services at the Sunyani Municipal Hospital participated in the study. One hundred and thirteen $(35.7 \%)$ of them were aged $25-29$ years, 163 (51.6\%) had basic level education and $69.0 \%(218 / 316)$ were self-employed. Most of the women $(57.9 \%, 183 / 316)$ were married (Table 1$)$. As at the time of the study, 76.4\% (120/316) of the women in their third trimester of pregnancy had made four or more ANC visits, whilst majority of those in their first trimester $(83.3 \%, 15 / 316)$ were coming for their second visit. Ninety-four (29.7\%) of the women had not delivered before, whilst 137 (43.4\%) of them have had more than one delivery (Table 1), with $31.3 \%$ (99) of them carrying their third pregnancy.

\section{Malaria prevention and food practices among the pregnant women}

A total of $278(88.0 \%)$ of the women indicated that they own at least one insecticide treated bed net, with $69.1 \%$
$(192 / 278)$ of them sleeping under a net the night before the data collection. All the women had received Intermittent Preventive Treatment in Pregnancy involving sulfadoxine-pyrimethamine (IPTp-SP) during the most recent pregnancy with $80.1 \%$ (253/316) of them taking the first dose during the second trimester, whilst $63(19.9 \%)$ of them received the drug during the third trimester. Most of the women $(96.5 \%, 305 / 316)$, also received iron supplements. Out of the 316 women, only 76 (24.1\%) had received anti-helminths medication during the current pregnancy. A total of $62(19.6 \%)$ of the women have had malaria infection during the current pregnancy with most of them (66.1\%) being infected during the second trimester (Table 2). Twenty (6.3\%) of the women never ate eggs during their current pregnancy whilst 19 (6.0\%) never consumed fish or snails during the current pregnancy.

\section{Prevalence of anaemia among the pregnant women}

Out of the 316 participants, 129 (40.8\%) were found to be anaemic $(\mathrm{Hb}<11.0 \mathrm{~g} / \mathrm{dl})$ at the time of their first ANC visit (mean Hb: $11.21 \mathrm{~g} / \mathrm{dl}$, range 6.8-15.1 g/dl). Seventynine $(61.2 \%)$ of them had mild anemia ( $\mathrm{Hb} 9.0-10.9 \mathrm{~g} /$ $\mathrm{dl}), 48(37.2 \%)$ had moderate anemia $(\mathrm{Hb} 7.0-8.9 \mathrm{~g} / \mathrm{dl})$ whilst $2(1.6 \%)$ had severe anemia $(\mathrm{Hb}<7.0 \mathrm{~g} / \mathrm{dl})$. During their most recent ANC visit, the prevalence of anaemia was found to be similar to that of the first visit with 131 $(41.5 \%)$ of them being anaemic $(\mathrm{Hb}<11.0 \mathrm{~g} / \mathrm{dl})$ [mean $\mathrm{Hb}: 11.24 \mathrm{~g} / \mathrm{dl}$, range $8.10-14.5 \mathrm{~g} / \mathrm{dl}]$. The prevalence of moderate anaemia reduced form $37.2 \%$ (CI 28.9-46.2) during the first visit to $19.1 \%$ (12.7-26.9) during the most recent visit, a reduction of $48.7 \%$ (Fig. 1).

\section{Factors associated with anaemia among the pregnant women}

Three main factors were found to be associated with anaemia among the pregnant women. These were, malaria infection, frequency at which one consumed fish/snails [sources of protein] and gestational age at first ANC visit. The number of deliveries, gestational age at which IPTp-SP was taken and iron supplementation did not seem to be associated with anaemia in pregnancy in the current study.

There was a significant difference in the prevalence of anaemia between women who had malaria infection and those who did not, with those infected being 7.2 times more likely to be anaemic than those who were not infected $(\mathrm{P}=0.008)$ (Tables 3,4$)$. Similarly, not eating fish/snails made the women more vulnerable to developing anaemia with those who did not take any fish/snails being 8.6 times more likely to become anaemic; with those who ate fish/snails for three or more times per week being more protected against anaemia $(P=0.02)$ (Tables 3, 4). 
Table 1 Background characteristics of study participants

\begin{tabular}{|c|c|c|c|}
\hline \multicolumn{2}{|l|}{ Variable } & Frequency $(\mathrm{N}=316)$ & Percentage \\
\hline \multicolumn{4}{|l|}{ Age category (years) } \\
\hline $15-19$ & \multicolumn{2}{|l|}{21} & 6.7 \\
\hline \multicolumn{2}{|l|}{$20-24$} & 61 & 19.3 \\
\hline $25-29$ & & 113 & 35.7 \\
\hline \multicolumn{2}{|l|}{$30-34$} & 78 & 24.7 \\
\hline \multicolumn{2}{|l|}{35 and above } & 43 & 13.6 \\
\hline \multicolumn{4}{|c|}{ Highest educational level } \\
\hline \multicolumn{2}{|l|}{ No formal education } & 22 & 7.0 \\
\hline \multicolumn{2}{|l|}{ Primary } & 163 & 51.6 \\
\hline Secondary & & 83 & 26.3 \\
\hline \multicolumn{2}{|l|}{ Tertiary } & 48 & 15.2 \\
\hline Occupation of particip & pants & & \\
\hline Government worker & 44 & & 13.9 \\
\hline Self employed & 218 & & 69.0 \\
\hline Unemployed & 30 & & 9.5 \\
\hline Other (students) & 24 & & 7.6 \\
\hline Marital status & & & \\
\hline Single & 50 & & 15.8 \\
\hline Married & 183 & & 57.9 \\
\hline Cohabitation & 79 & & 25.0 \\
\hline $\begin{array}{l}\text { Divorced/separation } \\
\text { widowed }\end{array}$ & / & & 1.3 \\
\hline Parity & & & \\
\hline Para zero & 94 & & 29.7 \\
\hline Primigravidae & 85 & & 26.9 \\
\hline Multigravidae & 137 & & 43.4 \\
\hline No. of ANC visits & Gestational ag & & \\
\hline & $\begin{array}{l}\text { 1st trimester } \\
\text { n (\%) }\end{array}$ & $\begin{array}{l}\text { 2nd trimester } \\
\text { n (\%) }\end{array}$ & $\begin{array}{l}\text { 3rd trimester } \\
\text { n (\%) }\end{array}$ \\
\hline Two & $15(83.3)$ & $51(36.2)$ & $12(7.6)$ \\
\hline Three & $3(16.7)$ & $61(43.2)$ & $25(15.9)$ \\
\hline Four or more & $0(0)$ & $29(20.6)$ & $120(76.4)$ \\
\hline Total & $18(100)$ & $141(100)$ & $157(100)$ \\
\hline
\end{tabular}

There was also a significant difference in the level of anaemia between women who made their first ANC visit during the first trimester and those who made the first visit during the second or third trimesters. Women who visited during the first trimester were 8.2 times more protected than those who visited later during the pregnancy $(\mathrm{P}=0.016)$ (Table 3$)$.

\section{Discussion}

Anemia in pregnancy is an important public health problem as it impacts not only on the pregnant woman but also significantly affects the unborn child. A cross sectional study was carried out in the Sunyani Municipal Hospital in Ghana to determine the prevalence
Table 2 Medical interventions and malaria infections during pregnancy

\begin{tabular}{|c|c|c|}
\hline Factors & Frequency $\mathrm{N}=316$ & $\%[95 \% \mathrm{Cl}]$ \\
\hline \multicolumn{3}{|l|}{ Bed net ownership } \\
\hline Own a bed net & 278 & $88.0[83.9-91.3]$ \\
\hline Does not own a bed net & 38 & $12.0[8.7-16.1]$ \\
\hline \multicolumn{3}{|l|}{ Bed nets use } \\
\hline $\begin{array}{l}\text { Slept under bed net the previ- } \\
\text { ous night }\end{array}$ & 192 & $60.8[55.1-66.2]$ \\
\hline $\begin{array}{l}\text { Did not sleep under bed net } \\
\text { last night }\end{array}$ & 124 & $39.2[33.8-44.9]$ \\
\hline \multicolumn{3}{|c|}{ Gestational age at which IPT1 was taken } \\
\hline Second trimester & 253 & $80.1[75.2-84.3]$ \\
\hline Third trimester & 63 & $19.9[15.7-24.8]$ \\
\hline \multicolumn{3}{|l|}{ Use of anti-helminthes } \\
\hline No dewormer received & 240 & $75.9[70.8-80.6]$ \\
\hline $\begin{array}{l}\text { At least one dose of dewormer } \\
\text { received }\end{array}$ & 76 & $24.1[19.4-29.2]$ \\
\hline \multicolumn{3}{|l|}{ Malaria infection during pregnancy } \\
\hline Been infected & 62 & $19.6[15.4-24.4]$ \\
\hline Not been infected & 254 & $80.4[75.6-84.6]$ \\
\hline \multicolumn{3}{|c|}{ Gestational age malaria infection occurred } \\
\hline First trimester & 8 & $12.9[5.7-23.9]$ \\
\hline Second trimester & 41 & $66.1[53.0-77.7]$ \\
\hline Third trimester & 13 & $21.0[11.7-31.2]$ \\
\hline
\end{tabular}

of aneamia and associated factors among antenatal (ANC) attendants. The prevalence of anaemia in this study was $41.5 \%$, with factors such as gestational age at first ANC visit, malaria infection and consumption of fish and snails being significantly association with the condition.

The level of anaemia found in this study was within global ranges (42-44\%) [9] as well as ranges reported from other parts of Africa (40\%) in Northwest Ethiopia [10], 57.3\% in South Africa, 66\% in Burkina Faso [11]. It is evident from the current study that the prevalence of anaemia in pregnancy is still high in the Sunyani Municipality despite various interventions including free distribution of insecticide treated nets [12], regular iron supplementation and improved antenatal care [13]. Although the level of anaemia in the current study is much lower than that reported by Dei-Adomakoh, and colleagues, it is high enough to be of public health concern as depending on the severity and duration of anemia and the stage of gestation, it can result in several adverse effects including low birth weight and preterm delivery [14].

Parasitic infections especially malaria and helminths during pregnancy have been associated with increased risk of maternal anaemia and adverse pregnancy outcomes [15]. It is well known that anaemia is a 


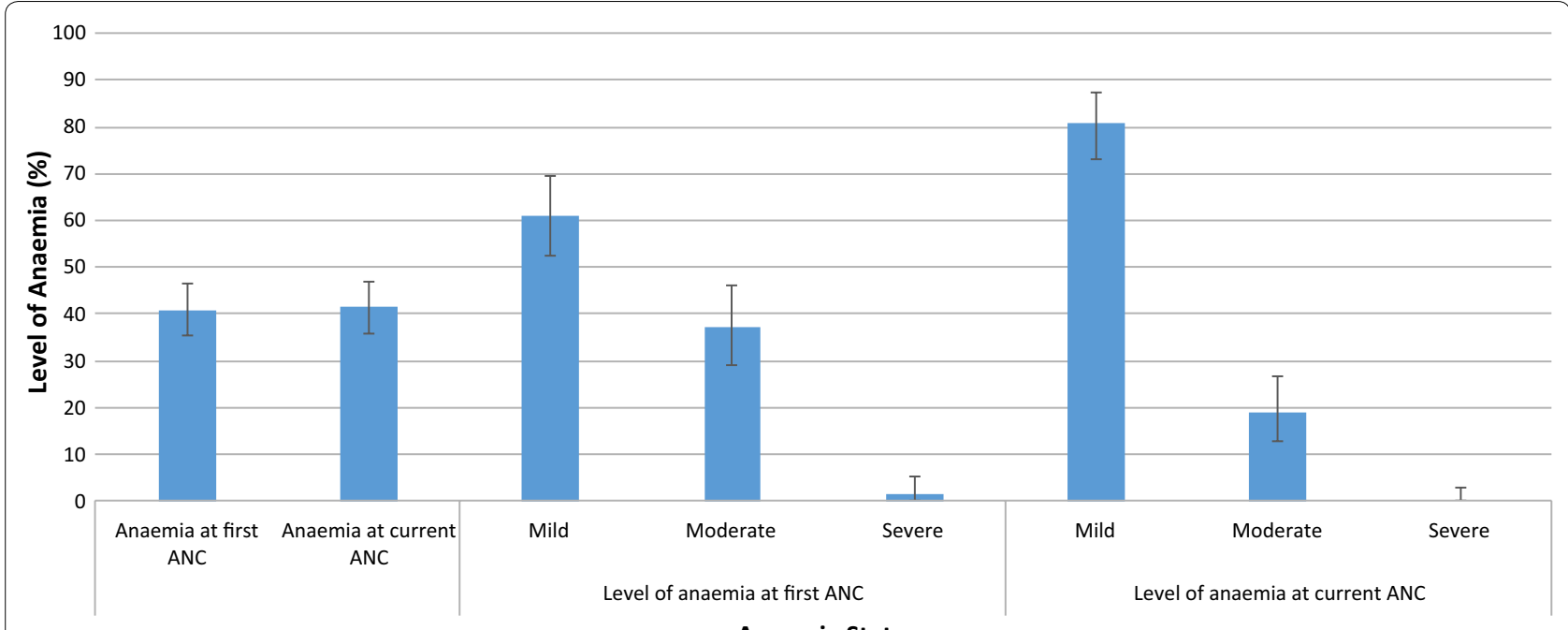

Anaemia Status

Fig. 1 Anaemia among ANC attendants at the Sunyani Municipal Hospital, May 2015. The points plotted (end of bars) indicate the level of anaemia. The vertical lines show the corresponding 95\% confidence intervals

Table 3 Some factors contributing to anemia in pregnancy among ANC attendants in the Sunyani Municipal Hospital

\begin{tabular}{|c|c|c|c|c|}
\hline Factors & Anaemia N (\%) & $\begin{array}{l}\text { Not anaemic } \\
\mathrm{N}(\%)\end{array}$ & $x^{2}$ & $P$ \\
\hline \multicolumn{5}{|c|}{ Number of ANC visits } \\
\hline Two visit & $37(47.4)$ & $41(52.6)$ & 5.31 & 0.07 \\
\hline Three visit & $28(31.6)$ & $61(68.4)$ & & \\
\hline $\begin{array}{l}\text { Four or more } \\
\text { visit }\end{array}$ & $66(44.3)$ & $83(55.7)$ & & \\
\hline \multicolumn{5}{|l|}{ Parity } \\
\hline Para zero & $45(47.9)$ & $49(52.1)$ & 2.943 & 0.230 \\
\hline Primigravidae & $30(35.3)$ & $55(64.7)$ & & \\
\hline Multigravidae & $56(40.9)$ & $81(59.1)$ & & \\
\hline \multicolumn{5}{|c|}{ Malaria infection during pregnancy } \\
\hline Been infected & $35(56.5)$ & $27(43.5)$ & 7.15 & 0.008 \\
\hline $\begin{array}{l}\text { Not been } \\
\text { infected }\end{array}$ & $96(37.8)$ & $158(62.2)$ & & \\
\hline \multicolumn{5}{|c|}{ Frequency of consuming fish/snail } \\
\hline Never & $12(63.2)$ & $7(36.8)$ & 8.55 & 0.04 \\
\hline Once a week & $15(50.0)$ & $15(50.0)$ & & \\
\hline Twice per week & $52(45.2)$ & $63(54.8)$ & & \\
\hline $\begin{array}{c}\text { Three or more } \\
\text { per week }\end{array}$ & $52(34.2)$ & $100(65.8)$ & & \\
\hline \multicolumn{5}{|c|}{ Gestational age at first visit } \\
\hline First trimester & $72(36.2)$ & $127(63.8)$ & 8.222 & 0.016 \\
\hline $\begin{array}{l}\text { Second } \\
\text { trimester }\end{array}$ & $57(49.6)$ & $58(50.4)$ & & \\
\hline Third trimester & $2(100)$ & $0(0)$ & & \\
\hline
\end{tabular}

serious clinical manifestation of malaria and results from increased destruction of both infected and uninfected red blood cells due to membrane alterations [16] and also ingestion of the cytoplasm of the red blood cells by the Plasmodium parasite [17]. It was therefore not surprising that women who had malaria during pregnancy were about five times more likely to be anaemic than those who did not.

Several studies [18-22] have found association between malaria infection and anaemia in pregnancy. As infection by malaria parasites and destruction of red blood cells is central to the reproduction and survival of the parasite. This relationship between malaria infection and anaemia in pregnancy is critical in the health of women in their reproductive age especially in malaria endemic areas. The already existing interventions (ITN usage, IPTp-SP, iron supplementation, deworming, indoor residual spraying), would have to be strengthened as they have proven to be effective $[22,23]$ in earlier studies.

It is worth noting that most of the women made their first ANC visit during the first trimester of pregnancy with only a few (2\%) making the first visit very late in the third trimester. Visiting ANC early in pregnancy reduced the likelihood of being anaemic. Early and regular antenatal visits are essential [24] as this could allow for the correction of anaemia that might exist even before the pregnancy. This essentially is achieved through iron supplementation as it is taken regularly throughout the pregnancy and supplies replenished during subsequent ANC visits. Thus, pregnant women who do not go for ANC regularly may not have the full benefit of iron supplementation. Also, early ANC visits will allow for prompt treatment of malaria infections which are usually more common during the early stages of pregnancy [25] and predisposes the pregnant woman to anaemia [26]. 
Table 4 Association between anemia, dietary habit, ANC visits, iron supplementation, malaria prevention and infection

\begin{tabular}{|c|c|c|c|c|c|c|}
\hline Variables & COR & $95 \% \mathrm{CL}$ & $\mathbf{P}$ & AOR & $95 \% \mathrm{Cl}$ & $\mathbf{P}$ \\
\hline \multicolumn{7}{|l|}{ IPTp-SP } \\
\hline No SP taken & 1.0 & & & & & \\
\hline At least one dose of SP & 0.64 & $0.38-.07$ & 0.09 & & & \\
\hline \multicolumn{7}{|l|}{ Frequency of taking meat, fish/snail } \\
\hline Never & 1.0 & & & 1.0 & & \\
\hline Once a week & 0.58 & $0.18-1.89$ & 0.37 & 1.03 & $0.42-2.54$ & 0.95 \\
\hline Twice per week & 0.48 & $0.18-1.31$ & 0.15 & 0.70 & $0.29-1.69$ & 0.43 \\
\hline Three or more times per week & 0.30 & $0.11-0.82$ & 0.02 & 2.15 & $0.58-7.98$ & 0.25 \\
\hline \multicolumn{7}{|c|}{ Iron supplementation taken during pregnancy } \\
\hline Received iron supplementation & 1.0 & & & & & \\
\hline Received no iron supplementation & 0.8 & $0.23-2.79$ & 0.73 & & & \\
\hline \multicolumn{7}{|l|}{ Gestational age at which IPT was taken } \\
\hline Third trimester & 1.0 & & & & & \\
\hline First trimester & 0.76 & $0.43-1.31$ & 0.32 & & & \\
\hline Second trimester & 1.43 & $0.73-2.80$ & 0.29 & & & \\
\hline \multicolumn{7}{|l|}{ Malaria infection during pregnancy } \\
\hline Been infected & 1.0 & & & 1.0 & & \\
\hline Not been infected & 0.47 & $0.27-0.82$ & 0.008 & 0.47 & $0.25-0.90$ & 0.021 \\
\hline \multicolumn{7}{|l|}{ Number of ANC visit } \\
\hline Two visits & 1.0 & & & 1.0 & & \\
\hline Three visits & 0.04 & $0.27-0.96$ & 0.04 & 0.65 & $0.32-1.32$ & 0.24 \\
\hline Four or more visits & 0.51 & $0.51-1.53$ & 0.65 & 0.89 & $0.48-1.61$ & 0.70 \\
\hline
\end{tabular}

Pregnant women who consumed fish or snails regularly were less likely to become anaemic compared to those who never consumed fish or snails. Nutritional anaemia is known to be the most common type of anaemia [27] with pregnant women who take less than two meals a day, less diverse meals or less meat being more likely to be anaemic. Thus, balanced diet involving meat and vegetable [28] and eggs [29] is essential during pregnancy in preventing anaemia.

The prevalence of anaemia is known to vary with the seasons and highest at the end of the malaria transmission season (just before the start of dry season). The main limitation of this study is that it was carried out at the beginning of the high malaria transmission season and covered only 2 months. Similarly, since eligibility was based on having had at least two ANC visits including the most recent one, for some women both visits (i.e., first and most recent) could be in the same trimester. This could reduce the true change in prevalence of anaemia between the first visit to the most recent one. These limitations notwithstanding, the study has been able to identify some of the factors associated with anaemia in pregnancy in the study area (Additional files 1,2).

\section{Conclusions}

Three main factors, malaria infection, frequency at which one consumed fish/snails and gestational age at first ANC visit were found to be significantly associated with anaemia among the pregnant women. The number of deliveries, gestational age at which IPTp-SP was taken and iron supplementation did not seem to be associated with anaemia in pregnancy in the current study. Strengthening malaria prevention, improving upon dietary intake and regular monitoring of haemoglobin levels during pregnancy could help reduce anaemia in this vulnerable population. This is in line with the current policy of free long lasting insecticidal net distribution to pregnant women during ANC visits to prevent malaria and also the increase in the recommended minimum IPT-p doses-from two to three-by the WHO and three to five by the Ghana Health Service. Well designed health education messages and programmes could also help improve uptake and usage of these intervention. Through the existing comprehensive ANC services, individualized dietary programmes can be drawn for identified pregnant women all directed at reducing anaemia and improving pregnancy outcomes. 


\section{Additional files}

Additional file 1. Anaemia in pregnancy-Sunyani.

Additional file 2. Data collection form.

\section{Abbreviations}

ANC: Antenatal Clinic; AOR: adjusted odds ratio; COR: crude odds ratio; CL: confidence interval; WHO: World Health Organization; Hb: haemoglobin; IPT: Intermittent Preventive Treatment; MCH: Maternal and Child Health; SP: sulphadoxine pyrimethanine; SMH: Sunyani Municipal Hospital; OPD: Outpatient Department.

\section{Authors' contributions}

PA compiled the data, performed the statistical analyses and drafted the manuscript. FA developed the research question, supervised the study design, contributed to the data analysis, interpretation of the results and revised the manuscript. Both authors read and approved the final manuscript.

\section{Author details}

${ }^{1}$ School of Public Health, University of Ghana, Legon, Ghana. ${ }^{2}$ Sunyani Municipal Hospital, Sunyani, Ghana.

\section{Acknowledgements}

The authors are particularly grateful to the management of the Sunyani Municipal Hospital especially Mrs. Mary Boakye the Matron and staff of the ANC unit especially Mrs. Victoria Dery, Asantewaa Boachie Linda and Frempong Pepertual who helped significantly during the conduct of the study.

\section{Competing interests}

The authors declare that they have no competing interests.

\section{Availability of data and materials}

The datasets supporting the conclusions of this article are included within the article and its additional files.

\section{Consent for publication}

Note applicable.

\section{Ethical approval and consent to participate}

Ethical approval for this study was obtained from the Ghana Health Service Ethical Review Committee (Number; GHS-ERC: 08/02/15). Permission was also sought from the management of the Sunyani Municipal Hospital before commencement of the study. The purpose of the study was explained to each study participant. Written informed consent was obtained from each participant. For participants $<18$ years, they were followed to their homes after ANC to obtain written parental consent (from their mothers) before data collection. Such participants also gave assent to be part of the study. To ensure confidentiality of participants' information, anonymous typing was used where by the names of the participants and any personal identifier were not collected. Also, participants were interviewed individually in an office provided by the hospital administration. Data access was limited to the principal investigator, research assistants and supervisor of the study only. All data collected were stored under lock and key.

\section{Funding}

No external funding was received for this study.

\section{Publisher's Note}

Springer Nature remains neutral with regard to jurisdictional claims in published maps and institutional affiliations.

Received: 22 November 2016 Accepted: 8 August 2017

Published online: 11 August 2017

\section{References}

1. World Health Organization. Iron deficiency anemia; assessment, prevention and control: a guide to programme managers. WHO/NHD/01.3. 2001. http://www.who.int/nutrition/publications/en/ida_assessment_ prevention_control.pdf. Accessed 29 June 2016.

2. Chathuranga G, Balasuriya T, Perera R. Anaemia among female undergraduates residing in the hostels of University of Sri Jayewardenepura, Sri Lanka. Anemia. 2014. doi:10.1155/2014/526308.

3. Goonewardene M, Shehata M, Hamad A. Anaemia in pregnancy. Best Pract Res Clin Obstet Gynaecol. 2012;26(Suppl 1):3-24. doi:10.1016/j. bpobgyn.2011.10.010.

4. Rush D. Nutrition and maternal mortality in the developing world. Am J Clin Nutr. 2000;72(Suppl 1):212-40.

5. Khan KS, Wojdyla D, Say L, Gülmezoglu AM, Van Look PF. WHO analysis of causes of maternal death: a systematic review. Lancet. 2006. doi:10.1016/ s0140-6736(06)68397-9.

6. Bondevik GT, Eskeland B, Ulvik RJ, Ulstein M, Lie RT, Schneede J, Kvåle G. Anaemia in pregnancy: possible causes and risk factors in Nepali women. Eur J Clin Nutr. 2000;54(1):3-8.

7. Brong Ahafo Reginal Health Directorate Annual Report. 2013.

8. Cochran WG. Sampling techniques. 3rd ed. New York: Wiley; 1977.

9. Chrispinus SM. Anaemia in pregnancy: prevalence and possible risk factors in Kakamega County, Kenya. Sci J Public Health. 2014;2(3):216. doi:10.11648/j.sjph.20140203.23.

10. Melku M, Addis Z, Alem M, Enawgaw B. Prevalence and predictors of maternal anemia during pregnancy in Gondar, Northwest Ethiopia: an institutional based cross-sectional study. Anemia. 2014;2014:108593. doi:10.1155/2014/108593.

11. Meda N, Mandelbrot L, Cartoux M, Dao B, Ouangré A, Dabis F. Anaemia during pregnancy in Burkina Faso, west Africa, 1995-1996: prevalence and associated factors. DITRAME study group. Bull World Health Organ. 1999;77(11):916-22.

12. Browne EN, Maude GH, Binka FN. The impact of insecticide-treated bednets on malaria and anaemia in pregnancy in Kassena-Nankana district, Ghana: a randomized controlled trial. Trop Med Int Health. 2001;6(9):667-76.

13. Dei-Adomakoh Y, Acquaye JK, Ekem I, Segbefia C. Second trimester anaemia in pregnant Ghanaians. West Afr J Med. 2014;33(4):229-33.

14. Di Renzo GC, Spano F, Giardina I, Brillo E, Clerici G, Roura LC. Iron deficiency anemia in pregnancy. Womens Health. 2015;11(6):891-900. doi:10.2217/whe.15.35.

15. Mahande AM, Mahande MJ. Prevalence of parasitic infections and associations with pregnancy complications and outcomes in northern Tanzania: a registry-based cross-sectional study. BMC Infect Dis. 2016;16(1):78. doi:10.1186/s12879-016-1413-6.

16. Narla M, Xiuli A. Malaria and human red blood cells. Med Microbiol Immunol. 2012;4:593-8. doi:10.1007/s00430-012-0272-z.

17. Tilley L, Dixon MW, Kirk K. The Plasmodium falciparum-infected red blood cell. Int J Biochem Cell Biol. 2011;43(6):839-42. doi:10.1016/j. biocel.2011.03.012.

18. Marchant T, Armstrong SJR, Edgar T, Ronsmans C, Nathan R, Abdulla S, Mukasa O, Urassa H, Lengeler C. Anaemia during pregnancy in southern Tanzania. Ann Trop Med Parasitol. 2002;96(5):477-87.

19. van Eijk AM, Hamel MJ, Parise M, Ayisi JG, Otieno K, Kager PA, Slutsker L. Malaria and anaemia among pregnant women at first antenatal clinic visit in Kisumu, western Kenya. Trop Med Int Health. 2007;12(12):1515-23.

20. Bankole HO, Omoregie R, Odia I, Oladeinde OB. Prevalence of malaria and anemia among pregnant women attending a traditional birth home in Benin City. Nigeria; Oman Med J. 2012;27(3):232-6. doi:10.5001/omj.2012.52.

21. Zoenabo D, Bisseye C, Djigma FW, Compaoré TR, Bazie VJT, Nikiema VPJB, Simpore J. Asymptomatic malaria correlates with anaemia in pregnant women at Ouagadougou, Burkina Faso. J Biomed Biotechnol. 2012. doi:10.1155/2012/198317.

22. Francine N, Damien B, Anna F, Michael K, Christevy VJ, Felix KK. Characterization of asymptomatic Plasmodium falciparum infection and its risk factors in pregnant women from the Republic of Congo. Acta Trop. 2016;153:111-5. doi:10.1016/j.actatropica.10.009. 
23. Nwaefuna EK, Afoakwah R, Orish VN, Egyir-Yawson A, Boampong JN. Effectiveness of intermittent preventive treatment in pregnancy with sulphadoxine-pyrimethamine against submicroscopic falciparum malaria in central region, Ghana. J Parasitol Res. 2015. doi:10.1155/2015/959427.

24. Ikeanyi EM, Ibrahim Al. Does antenatal care attendance prevent anemia in pregnancy at term? Niger J Clin Pract. 2015;18(3):323-7. doi:10.4103/1119-3077.151730.

25. Valea I, Tinto H, Drabo MK, Huybregts L, Sorgho H, Ouedraogo JB, Guiguemde RT, van Geertruyden JP, Kolsteren P, D'Alessandro U, FSP/ MISAME study Group. An analysis of timing and frequency of malaria infection during pregnancy in relation to the risk of low birth weight, anaemia and perinatal mortality in Burkina Faso. Malar J. 2012;11:71. doi:10.1186/1475-2875-11-71.

26. Cisse M, Sangare I, Lougue G, Bamba S, Bayane D, Guiguemde RT. Prevalence and risk factors for Plasmodium falciparum malaria in pregnant women attending antenatal clinic in Bobo-Dioulasso (Burkina Faso). BMC Infect Dis. 2014;14:631. doi:10.1186/s12879-014-0631-z
27. Abriha A, Yesuf ME, Wassie MM. Prevalence and associated factors of anemia among pregnant women of Mekelle town: a cross sectional study. BMC Res Notes. 2014;7:888. doi:10.1186/1756-0500-7-888.

28. Obse N, Mossie A, Gobena T. Magnitude of anemia and associated risk factors among pregnant women attending antenatal care in ShallaWoreda, West Arsi Zone, Oromia Region, Ethiopia. Ethiop J Health Sci. 2013;23(2):165-73.

29. Baig-Ansari N, Badruddin SH, Karmaliani R, Harris H, Jehan I, Pasha O, Moss N, McClure EM, Goldenberg RL. Anemia prevalence and risk factors in pregnant women in an urban area of Pakistan. Food Nutr Bull. 2008;29(2):132-9.

\section{Submit your next manuscript to BioMed Central and we will help you at every step:}

- We accept pre-submission inquiries

- Our selector tool helps you to find the most relevant journal

- We provide round the clock customer support

- Convenient online submission

- Thorough peer review

- Inclusion in PubMed and all major indexing services

- Maximum visibility for your research

Submit your manuscript at www.biomedcentral.com/submit 